\title{
CRECIMIENTO ECONÓMICO E INDUSTRIALIZACIÓN EN la Agenda 2030: PERspectivas para MÉXico
}

\author{
Alejandra Trejo Nieto ${ }^{1}$
}

Fecha de recepción: 06 de junio de 2016. Fecha de aceptación: 26 de septiembre de 2016.

\begin{abstract}
RESUMEN
En 2015, la Organización de las Naciones Unidas (ONU) aprobó una nueva agenda internacional para el desarrollo, la Agenda 2030 integrada por los 17 Objetivos de Desarrollo Sustentable y 169 metas. Esta agenda explicita la necesidad de acciones dirigidas a fortalecer el crecimiento económico sostenible, el empleo decente y la industrialización en todos los países. Este marco estratégico internacional resulta de particular trascendencia para México dado el contexto de bajo crecimiento, así como de relativo abandono de políticas activas de industrialización por más de tres décadas. El documento sitúa en retrospectiva, los problemas de crecimiento e industrialización en el país, e identifica retos y obstáculos, en el contexto nacional vigente, para alcanzar las metas estipuladas en los objetivos 8 y 9 de la Agenda 2030.
\end{abstract}

Palabras clave: crecimiento económico, industrialización, Agenda 2030, estudios prospectivos, indicadores económicos.

Clasificación JEL: E61, E66, F01, O11, O14.

\section{ECONOMIC GROWTH AND INDUSTRIALIZATION ON the 2030 Agenda: Prospects for Mexico}

\begin{abstract}
In 2015, the United Nations approved a new international development agenda, known as the 2030 Agenda, consisting of 17 Sustainable Development Goals and 169 targets. The agenda asserts the need for targeted actions to bolster sustainable economic growth, decent employment, and industrialization in all countries. This international strategic framework is of particular relevance to Mexico in light of its low-growth context, as well as its relative abandonment of active industrialization policies, for more than three decades now. This document provides a retrospective view of growth and industrialization in Mexico, and identifies challenges and obstacles in the current national context when it comes to achieving the targets set forth in Goals 8 and 9 on the 2030 Agenda.
\end{abstract}

Key Words: Economic growth, industrialization, 2030 Agenda, prospective studies, economic indicators.

1 El Colegio de México. Correo electrónico: abtrejo@colmex.mx 


\section{LA CROISSANCE ÉCONOMIQUE ET INDUSTRIALISATION DANS L'AGENDA 2030: PERSPECTIVES POUR LE MEXIQUE}

\section{Résumé}

En 2015, l'Organisation des Nations Unies (ONU) a approuvé un nouvel agenda international pour le développement. L'Agenda 2030 est compose des 17 objectifs de développement durable et 169 buts. Ce programme rend explicite la nécessité d'actions visant à renforcer la croissance économique soutenable, l'emploi decent et l'industrialisation dan tous les pays. Ce cadre stratégique international est d'une importance particulière pour le Mexique étant donné le contexte de faible croissance et de l'abandon relatif des politiques d'industrialisation actives depuis plus de trois déciennes. Le document situé en rétrospective les problèmes d'industrialisation et croissance du pays, et identifie les défis et les obstacles dans le contexte national actuel pour atteindre les objectifs fixés dans les objectifs 8 et 9 de l'ordre de l'Agenda 2030.

Mots clés: la croissance économique, l'industrialisation, l'Agenda 2030, des études prospectives, les indicateurs économiques.

\section{CRESCIMENTO ECONÔMICO E INDUSTRIALIZAÇÃo NA AGENDA 2030: PERS- PECTIVAS PARA O MÉXICO}

\section{Resumo}

Em 2015, a Organização das Naçóes Unidas (ONU) aprovou uma nova agenda internacional para o desenvolvimento, a Agenda 2030 está composta pelos 17 Objetivos de Desenvolvimento Sustentável e 169 metas. Esta agenda deixa explícita a necessidade de açóes dirigidas para reforçar o crescimento econômico sustentável, o emprego digno e a industrialização em todos os países. Este marco estratégico internacional é de particular importância para o México, dado o contexto de baixo crescimento e de abandono relativo das políticas ativas de industrialização por mais de três décadas. O documento lista problemas de crescimento e industrializaçáo do país, e identifica desafios e obstáculos, no contexto nacional atual, para atingir as metas definidas nos objetivos 8 e 9 da Agenda 2030.

Palavras-chave: crescimento econômico, industrialização, Agenda 2030, estudos prospectivos, indicadores económicos.

\section{墨西哥2030年经济增长和工业化展望 \\ 阿莱杭德拉・特雷霍 \\ 摘要}

2015年联合国通过了2030年国际发展议程，其中包括17项可持续发展目 标和169项发展目标。该议程明确了采取促进经济可持续增长、体面就业 和工业化措施的必要性。这一议程对墨西哥来说意义重大。墨西哥近年来 经济增长迟缓，且在近三十年间政府并未实施积极的促进工业化的措施。 本文回顾了墨西哥经济增长及工业化中遇到的问题, 并指出了在当前国情 下，实现2030年议程中第入和第九项目标所面临的挑战和阻碍。

关键词: 经济增长, 工业化, 2030年议程, 前瞻性研究, 经济指数 


\section{INTRODUCCIÓN}

En 2015, la Organización de las Naciones Unidas (ONU) aprobó una nueva agenda para el desarrollo. El documento "Transformar nuestro mundo: la Agenda 2030 para el desarrollo sostenible”, formaliza el plan de acción a favor del desarrollo internacional posterior a 2015 (onu, 2015). La Agenda 2030 se integró por 17 Objetivos -denominados Objetivos de Desarrollo Sustentable (oDs) - y por 169 metas. La Agenda de Desarrollo Post-2015 tuvo como antecedente los Objetivos de Desarrollo del Milenio (oDM) dentro de los que se ubicó la equidad de género, la educación, la infancia, la salud y la pobreza como temas prioritarios en la formulación de una agenda internacional para el desarrollo, dirigida principalmente a los países más pobres y bajo un esquema de cooperación. La Declaración del Milenio se convirtió formalmente en la base integradora y organizadora de las propuestas y acciones emprendidas por una gran parte de los actores del desarrollo a nivel internacional, y en varios casos a nivel doméstico. En el discurso y en la práctica se emprenderían numerosas iniciativas y actividades encaminadas a alcanzar las metas trazadas a 15 años en el marco de los odm.

$\mathrm{Al}$ acercarse el año 2015 se inició una etapa de debate acerca del futuro de los programas para el desarrollo mundial. La agenda internacional fue sometida a una especie de reingeniería ubicando entre sus ejes principales una serie de objetivos de desarrollo económico -fundamentados todos en un principio de sustentabilidad. Así, en la Agenda 2030 se encuentran el objetivo 8 -promover el crecimiento económico sostenido, inclusivo y sostenible, el empleo pleno y productivo, y el trabajo decente para todos-, y el objetivo 9 -construir infraestructuras resilientes, promover la industrialización inclusiva y sostenible, y fomentar la innovación. A través del establecimiento de objetivos y metas de desarrollo económico, la nueva agenda pretende impulsar políticas que aumenten la capacidad productiva, la productividad, el empleo y el desarrollo industrial a través de mejores infraestructuras y el desarrollo de innovaciones (ONU, 2015).

A diferencia de la anterior, la nueva agenda explicita la necesidad de acciones encaminadas a fortalecer las economías nacionales, marco que resulta crucial para países como México dado el contexto de bajo crecimiento en los últimos 30 años, así como del relativo abandono de políticas activas de industrialización, lo que ha debilitado la capacidad productiva del país. Asimismo, si bien las cifras en materia de desempleo se han mostrado muy bajas, las mismas ocultan problemas en el mercado laboral del país, como son: la informali- 
dad, la subocupación, la precariedad, los bajos salarios, la baja productividad, la segmentación, entre otros.

En el siglo xx, México experimentó importantes trasformaciones económicas al pasar de una sociedad predominantemente agrícola y rural, a una industrial y de servicios, mayoritariamente urbana. La economía experimentó en los años cincuenta, el periodo de crecimiento más alto y prolongado en la vida del nuevo país independiente. Sin embargo, a pesar de lograrse avances importantes en materia de industrialización y crecimiento, persisten numerosos problemas y rezagos vinculados con el subdesarrollo. Más que realizar un análisis comprehensivo del desarrollo económico mexicano, el objetivo de este documento es, por una parte, situar en retrospectiva los rasgos más problemáticos del proceso de industrialización y de crecimiento económico en el país. Por otra parte, se pretenden identificar los retos y obstáculos futuros en la materia. Esta última revisión se vincula primordialmente con la agenda internacional para el desarrollo al 2030, y las acciones y compromisos que el país asuma para el cumplimiento de sus objetivos al 2030 en el marco de implementación de reformas estructurales.

El presente documento inicia con un breve repaso sobre los modelos de desarrollo e industrialización, y la trayectoria de crecimiento económico. Luego se comenta el contenido conceptual de lo que se denomina agenda económica de los ods, i.e. los objetivos 8 y 9. Posteriormente, se retoman una serie de indicadores que se proponen para evaluar el cumplimiento de estos objetivos, y que sirven de base para establecer un primer acercamiento de la situación que guarda el caso mexicano en los rubros de crecimiento e industrialización. Luego se hace una breve exploración prospectiva en términos de los retos que enfrenta el país de cara a la Agenda 2030 en el contexto nacional vigente de implementación de nuevas reformas estructurales. Finalmente, se concluye con la sección de comentarios.

\section{CRECIMIENTO ECONÓMICO E INDUSTRIALIZACIÓN EN MÉXICO DEL DESARROLLISMO AL NEOLIBERALISMO}

En México, las estrategias de desarrollo nacional, de industrialización y de crecimiento económico han estado estrechamente vinculadas entre sí. En la etapa posrevolucionaria, la industrialización se entendió como la transformación de la base económica del país y como el pilar del crecimiento que llevaría a la urbanización de la sociedad. Según Haber (1993) se emprendió 
una segunda transición industrial que dio continuidad a la industrialización incipiente del siglo XIX que había sido interrumpida por el conflicto armado revolucionario.

Es a partir de la década de los cuarenta que el gobierno implementó una estrategia formal de desarrollo que a la luz de sus primeros resultados fue exitosa. Se impulsó la industrialización bajo el esquema de sustitución de importaciones: un desarrollo hacia adentro con una fuerte postura proteccionista-nacionalista. En el plano internacional, México se ubicaba como una nación en desarrollo, pero con avances alentadores en términos de su dinamismo macroeconómico. Mediante instrumentos de política industrial se generó una transferencia de recursos a sectores específicos de la industria manufacturera, los cuales se beneficiaron de reducciones impositivas: créditos, tasas de interés preferenciales, reembolsos de los derechos de importación y acceso a las cuotas de importación (Norris et al., 1999). Este periodo se caracterizó por la alta participación del Estado en la economía, así como de la banca nacional de desarrollo y los fondos de apoyo a la industria (Méndez, 1997).

A mediados de los años sesenta, la industria maquiladora-como parte del Programa de Industrialización Fronteriza- impulsó de manera importante la industrialización regional al sentar las bases industriales en numerosas ciudades cercanas a la frontera con Estados Unidos y generar empleo de corte industrial. De estos beneficios se favorecerían luego otras ciudades al interior del país. De esa forma entre los años cuarenta y sesenta ocurrió el mayor impulso a la actividad industrial, se alcanzó el "milagro mexicano" y la conversión a una sociedad urbana.

En los años sesenta, el sector industrial sobrepasó la participación de la agricultura en el valor agregado nacional total (véase gráfica 1). En 1965 la agricultura representó menos del $14 \%$ del valor añadido y la industria (incluyendo a la minería) casi $27 \%$. En los ańos posteriores se observa la participación decreciente de la agricultura y avances relativos de la industria, si bien a partir de 1988 la economía mexicana muestra una estructura fuertemente orientada a los servicios (incluyendo al comercio y el transporte).

Ya para finales de los años sesenta comenzaron a vislumbrarse importantes problemas estructurales que avisaban el debilitamiento del modelo de desarrollo nacional. El incremento del endeudamiento externo (1970-1976) y el auge petrolero (1978-1981) contribuyeron a la recuperación temporal de las tasas de crecimiento observadas durante décadas previas (Loría, 2009).

El cierre abrupto, a principios de los años ochenta, de la financiación del déficit externo que había gozado el país por parte de los bancos extranjeros, prestamistas privados e instituciones financieras internacionales, detonó la cri- 
Grática 1. Estructura sectorial del PIB (\%)

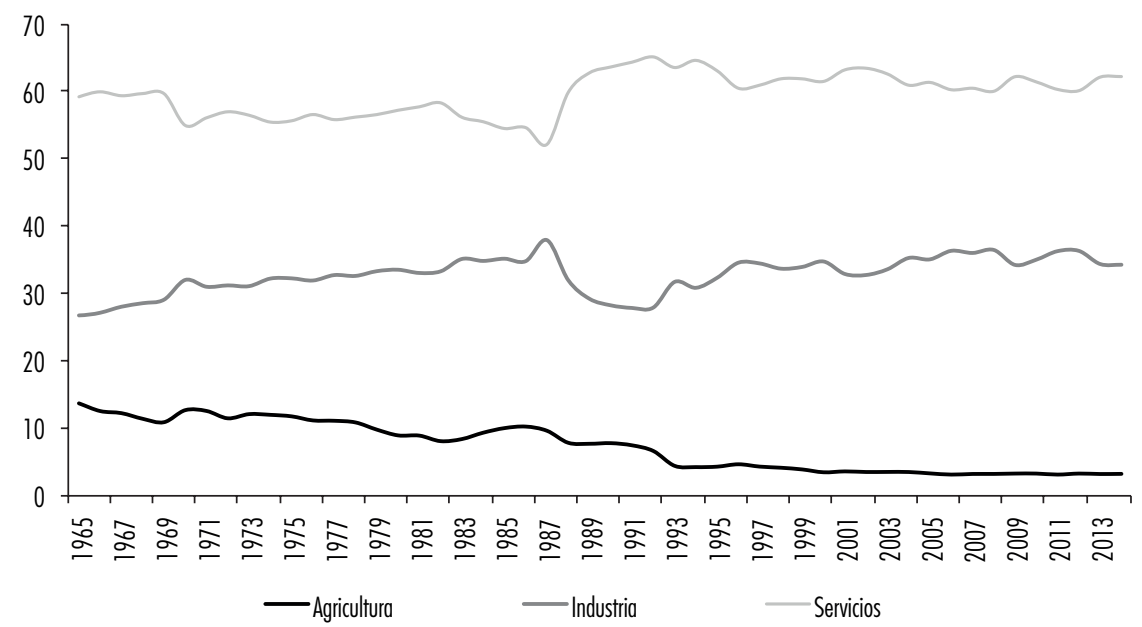

Fuente: elaboración propia con base en datos del Banco Mundial.

sis de la deuda externa. El restablecimiento de los créditos y la reprogramación del calendario para la deuda externa se condicionó al establecimiento de una serie de medidas de ajuste estructural, un programa completo de desregulación, privatización y liberalización económica. De ahí que la reorientación de la política económica y la formulación de un nuevo modelo de desarrollo industrializador, ante la decadencia de la sustitución de importaciones, fuera "dirigida" por los acreedores del gobierno mexicano a nivel internacional. Correspondió al gobierno emprender las medidas de ajuste y reformular la política económica bajo condiciones de inestabilidad. La nueva estrategia nacional priorizó la estabilidad macroeconómica - una baja inflación y un bajo déficit-, la receta de una "sana política económica" de las políticas neoliberales.

El Plan Nacional de Desarrollo 1983-1988 planteó expresamente la necesidad de reformas estructurales que favorecieran la exportación de manufacturas, que a su vez sería el motor del crecimiento nacional (Loría, 2009). En la práctica, el punto de arranque del proyecto de economía abierta fue el desmantelamiento del aparato proteccionista hasta alcanzar la adhesión de México al Acuerdo General sobre Aranceles Aduaneros y Comercio (GATT) en 1986. También dio inicio la privatización de las más de mil empresas públicas (Esparza, 2014).

Más tarde el plan económico se dirigió a ampliar y diversificar la base exportadora mexicana. A partir de 1987 los impuestos a la exportación y la cobertura de los controles de las exportaciones se redujeron. El programa de 
promoción exportadora incluyó incentivos a las exportaciones no petroleras, la reestructuración y simplificación de los procedimientos administrativos, mayor acceso a créditos y la reducción de las restricciones sobre el uso de los ingresos de exportación. El gobierno abandonó su vocación nacionalista y con ello sus esfuerzos para limitar la inversión extranjera directa.

Se desmanteló la política industrial (Moreno-Brid y Paunovic, 2009; Ros, 2010) y el Estado dejó de cumplir con su papel de promotor del desarrollo (Calderón y Sánchez, 2012). Los escasos intentos para promover políticas industriales activas (como el Programa Nacional de Fomento Industrial y Comercio Exterior (PRONAfICE) promulgado en 1984 y el Programa de Fomento Integral a las Exportaciones (PROFIEX) de 1985) fracasaron por la insuficiencia de los recursos para su implementación. Los instrumentos de apoyo por la vía de la inversión pública, el financiamiento y el estímulo fiscal desaparecieron. Se dejó a las "fuerzas del mercado", seleccionar qué empresas, sectores y territorios sobrevivirían a las nuevas circunstancias (ibid).

En los noventas, las reformas estructurales se intensificaron con privatizaciones adicionales y el país ingresó al Tratado de Libre Comercio de América del Norte (TLCAN), representando el punto del clímax en la estrategia de apertura comercial. Algunos indicadores resultaron alentadores: el comercio internacional creció en promedio $8.5 \%$ anual entre 1985 y 2012, y su participación en el Producto Interno Bruto (PIB) pasó de 33.7\% entre 1984 y 1993 a $6.3 \%$ entre 2010 y 2011. La inflación se mantuvo estable y bajo control, lo que acompañó a una disminución del déficit fiscal del gobierno como porcentaje del piв (Cárdenas, 2015).

Simultáneamente se evidenciaron limitaciones como el aumento de la dependencia externa, la presencia sistemática de déficits en la cuenta comercial de mercancías, crecientes déficits en cuenta corriente, desempeño diferenciado entre empresas y territorios. México se convirtió en una economía altamente abierta y liberalizada, y los pactos estabilizadores rompieron eficientemente el círculo vicioso inflación-devaluación-recesión, sin embargo, mostró una limitada capacidad para ampliar su capacidad productiva, generar empleo, impulsar el desarrollo, y fomentar el bienestar social.

Las últimas tres décadas y media la economía mexicana ha transitado por crisis recurrentes, y ha experimentado un crecimiento bajo e inestable, lo que puede identificarse como un estancamiento productivo (i.e. secuencia larga de crecimiento pobre o negativo). Aunque se presenta crecimiento significativo en 1996, 1997, 1998, 2000 y 2009, a dichas tasas las anteceden caídas importantes, principalmente en 1995. En las últimas dos décadas, el crecimiento del рів ha registrado una tasa promedio anual de sólo 2.7 por ciento (véase gráfica 2). 
Gráfica 2. Tasas de crecimiento del PIB real (\%) y línea de tendencia de largo plazo, 1940-2013

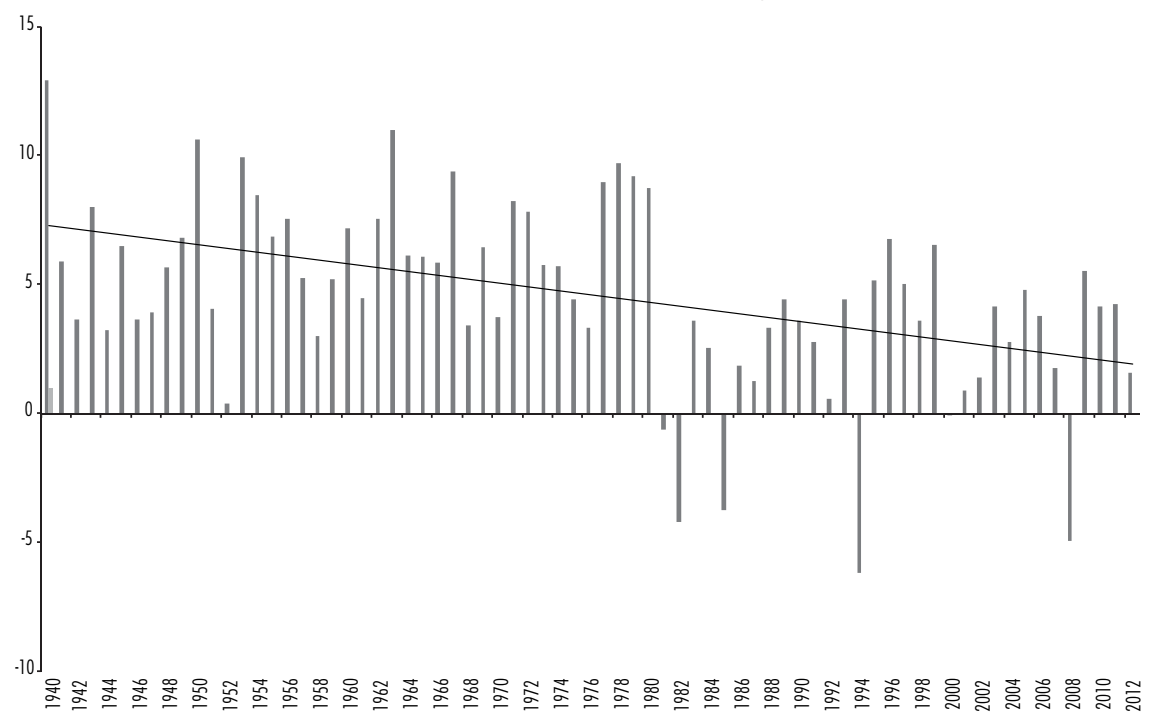

Fuente: elaboración propia con base en German-Soto (2015).

Por su parte, el PIB per cápita decreció en términos reales $1.8 \%$ promedio anual durante el periodo 1982-1987, y entre 1982 y 2013 creció anualmente $0.48 \%$, en contraste con el $3.29 \%$ anual experimentado de 1940 a 1981 (véase gráfica 3).

La evolución y estructura del mercado laboral mexicano han estado fuertemente direccionadas por las características del modelo económico en turno. Indicadores fundamentales como las tasas de desempleo, la ocupación y los salarios, expresan la respuesta y adaptación del mercado de trabajo ante los cambios en las políticas aplicadas (Cota y Navarro, 2015). El avance del empleo y los salarios entre los años cuarenta y setenta se había mantenido a la par del avance en materia de crecimiento del producto, aunque con un cambio en la estructura laboral por el avance del empleo industrial en detrimento del empleo primario.

A principios de los años ochenta la práctica laboral abrió paso a procesos de flexibilización como una tendencia originada en un entorno económico de crisis, y por las reformas tendientes a la liberalización, la privatización y la desregulación (Trejo y Saucedo, 2014). Vinculado con su flexibilización, el mercado laboral se ha caracterizado en las décadas recientes por el avance del sector informal lo que se ha explicado por la creciente precarización del empleo 
Gráfica 3. Tasas de crecimiento del PIB per cápita real (\%), 1940-2013

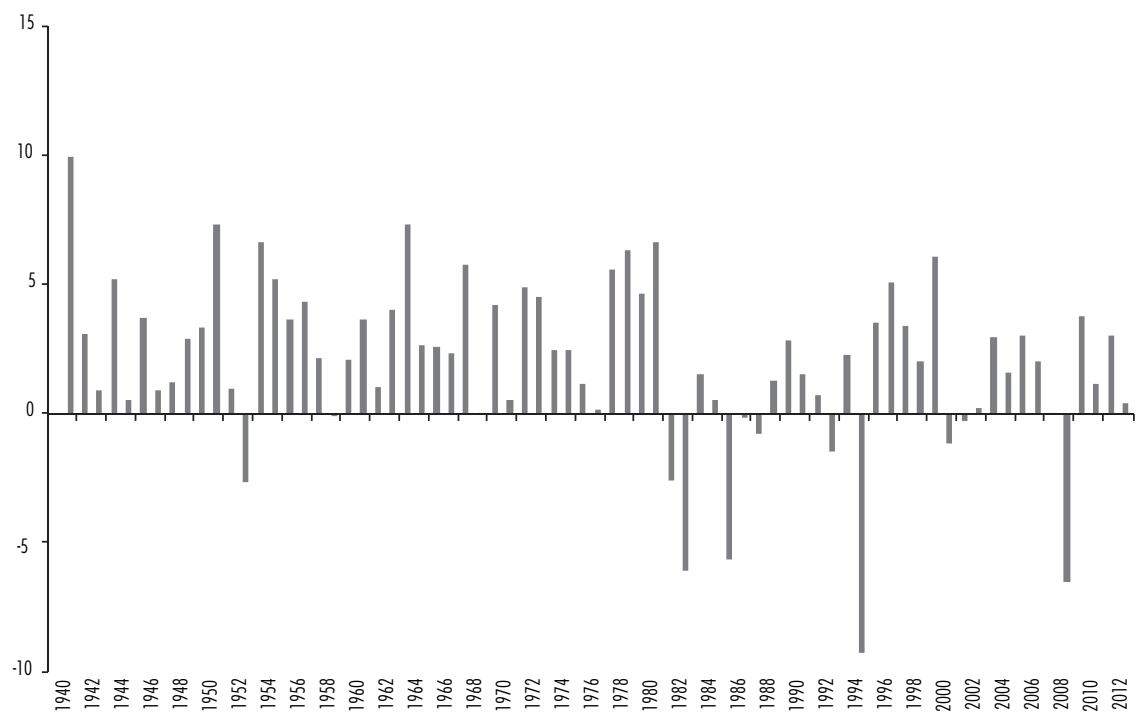

Fuente: elaboración propia con base en German-Soto (2015).

asalariado y la disminución de los salarios reales. $\mathrm{Al}$ incremento de la precarización, se sumó la pérdida de la gestión sindical, y la nula o mala gestión de la política industrial (Huesca, 2005 citado en Cota y Navarro, 2015), elementos que contribuyeron a minar la capacidad de absorción y la calidad del empleo.

En la última década numerosas economías occidentales han enfrentado un escaso crecimiento económico y una creciente vulnerabilidad externa, lo cual ha motivado una preocupación internacional que se ha reflejado en la definición de una nueva agenda internacional para el desarrollo. Por su parte, México experimenta un pobre crecimiento desde finales de los ańos setenta, por lo que en torno a este problema se pretende articular parte de la agenda para la formulación de reformas y políticas públicas del país.

\section{UNA “AGENDA ECONÓMICA” EN EL MARCO DE LOS OBJETIVOS DE DESARROLLO SOSTENIBLE}

En la agenda de desarrollo internacional 2015, la erradicación de la pobreza se ubicó de forma explícita como el principal de los desafíos de la comunidad internacional. Pero un renovado interés y preocupación por el crecimiento productivo tanto de países en desarrollo como de naciones desarrolladas cobró 
fuerza a raíz de las crisis financieras y económicas internacionales de 2008 y 2009 cuando se evidenció la significativa vulnerabilidad e inestabilidad económica de numerosos países como consecuencia de la profunda interconexión de las entidades económicas y financieras a nivel global. Fue entonces cuando se comenzaron a plantear posibles ajustes necesarios en los planos internacional, nacional y local. Cierto optimismo sobre el crecimiento económico mundial en los años previos a la crisis respondió a la presencia de tasas de crecimiento relativamente altas en distintos países en desarrollo, incluso africanos. De 2002 a 2007 se registró un incremento en el consumo en países desarrollados y un boom exportador y de inversión extranjera en países emergentes, liderados por China. Estas dinámicas fomentaron confianza y subestimaron los riesgos de mantener una economía global sustentada en elevados flujos de crédito (Verick e Islam, 2010). La gráfica 4 muestra la evolución del crecimiento económico mundial y de sus principales regiones a partir de 2000. En ella se observan tasas de crecimiento reducidas en los países desarrollados y la dificultad de recuperar los ritmos de crecimiento previos a 2007.

Por su parte, el informe de la Organización Internacional del Trabajo (oIT) sobre el trabajo en el mundo 2011 estimó que aunque tras la crisis de 2008 se requería generar 80 millones de empleos entre 2012 y 2013 para alcanzar la

Gráfica 4. Crecimiento económico mundial y regional, 2000-2014 (\%)

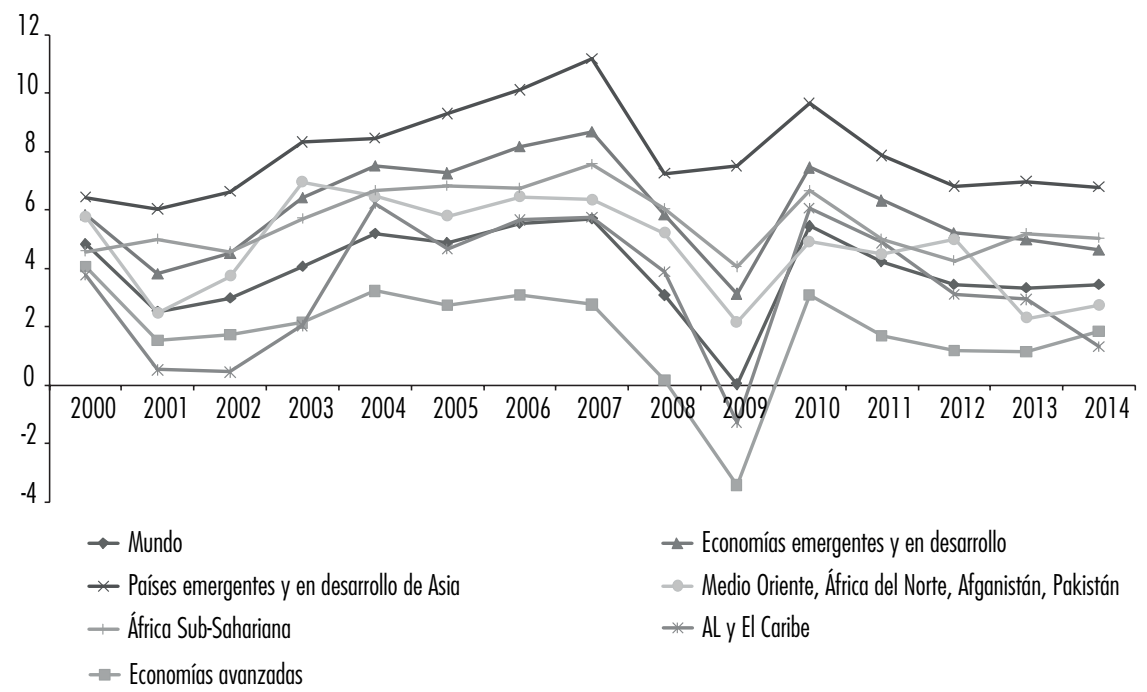

Fuente: IMF World Economic Outlook Database October 2015. 
tasa de desempleo de 2007, sólo se estaba en capacidad de generar 40 millones (IILU, 2011 citado en Trejo y Saucedo, 2013).

Según la Agenda 2030 el crecimiento económico y la industrialización -a través de los objetivos 8 y 9- se posicionan como vectores fundamentales del desarrollo de las naciones, bajo el precepto de que una forma de vida próspera, de alta calidad, sostenible y equitativa es alcanzable mediante la transformación de las estructuras económicas, el incremento de la productividad y el empleo, el trabajo decente, así como la innovación y el mejoramiento de las infraestructuras. La formulación de los ods 8 y 9 plantea además un giro cualitativo a la concepción del crecimiento económico asignando a éste un carácter de inclusividad y sostenibilidad. ${ }^{2}$

Por su parte, la industrialización y el desarrollo industrial se conciben no sólo a partir de un proceso de recomposición sectorial sino del desarrollo de nuevos sistemas tecnológicos y de producción, la generación constante nuevas actividades de rápido crecimiento y caracterizadas por un alto valor añadido y productividad. La infraestructura se erige como soporte del crecimiento y el desarrollo industrial que contribuye a mejorar la productividad, a generar economías de aglomeración y a reducir los costos de la actividad económica (onU, 2015). En esta visión del crecimiento y expansión industrial se incorpora el principio de trabajo decente para toda la fuerza laboral (véase cuadro 1).

Los dos objetivos y sus 20 metas se definen como la agenda económica de los ods en la discusión subsecuente de este trabajo. En su contenido detallado los objetivos 8 y 9 están orientados a alcanzar crecimiento sostenido, industrialización, pleno empleo y trabajo decente. Las metas establecen medios y acciones principalmente dirigidas a la diversificación productiva, la modernización tecnológica y la innovación; el fortalecimiento y acceso financiero en especial para atender a pequeñas y medianas empresas; el desarrollo de infraestructuras, gasto en investigación y desarrollo, tecnologías de la información; y las políticas de trabajo decente, racionalización de los recursos y sostenibilidad ambiental.

Las metas además de numerosas son problemáticas en su abordaje metodológico, y en la mayoría de los casos es complicado establecer parámetros de referencia tanto de la situación de partida como de evaluación de avance. Lo mismo sucede en términos de las políticas públicas a seguir al surgir contra- 


\section{Alejandra Trejo Nieto}

Cuadro 1. Objetivos 8 y 9 de la Agenda 2030

Objetivo

Metas

8. Promover el crecimiento económico sostenido, inclusivo y sostenible, el empleo pleno y productivo, y el trabajo decente para todos
1. Mantener el crecimiento económico pc, en particular, un crecimiento del PIB de al menos 7\% anual en los países menos adelantados.

2. Lograr niveles más elevados de productividad mediante la diversificación, la modernización tecnológica y la innovación, centrando la atención en sectores de mayor valor añadido y uso intensivo de mano de obra.

3. Promover políticas que apoyen las actividades productivas, la creación de empleo decente, el emprendimiento, la creatividad y la innovación; alentar la oficialización y el crecimiento de las microempresas y las pequeñas y medianas empresas, mediante el acceso a servicios financieros.

4. Mejorar progresivamente la producción y el consumo eficientes de los recursos mundiales y procurar desvincular el crecimiento económico de la degradación del medio ambiente, de conformidad con el marco decenal de programas sobre modalidades sostenibles de consumo y producción, empezando por los países desarrollados.

5. Lograr el empleo pleno y productivo, garantizar un trabajo decente para todos, y la igualdad de remuneración por trabajo de igual valor.

6. Reducir sustancialmente la proporción de jóvenes que no están empleados y no cursan estudios ni reciben capacitación.

7. Adoptar medidas para erradicar el trabajo forzoso, poner fin a las formas modernas de esclavitud y la trata de seres humanos, asegurar la prohibición y eliminación de las peores formas de trabajo infantil, incluidos el reclutamiento y la utilización de niños soldados; poner fin al trabajo infantil en todas sus formas.

8. Proteger los derechos laborales y promover un entorno de trabajo seguro y protegido para todos los trabajadores.

9. Elaborar y poner en práctica políticas encaminadas a promover un turismo sostenible que cree puestos de trabajo y promueva la cultura y los productos locales.

10. Fortalecer la capacidad de las instituciones financieras nacionales para alentar y ampliar el acceso a los servicios bancarios, financieros y de seguros para todos.

11. Aumentar la ayuda para el comercio en los países en desarrollo.

12. Desarrollar y poner en marcha una estrategia mundial para el empleo de los jóvenes y aplicar el Pacto Mundial para el Empleo de la OIT. 
9. Construir infraestructuras resilientes, promover la industrialización inclusiva y sostenible, y fomentar la innovación
1. Desarrollar infraestructuras fiables, sostenibles, resilientes y de calidad, incluidas infraestructuras regionales y transfronterizas, para apoyar el desarrollo económico y el bienestar humano, con especial hincapié en el acceso equitativo y asequible para todos.

2. Promover una industrialización inclusiva y sostenible; aumentar de manera significativa la contribución de la industria al empleo y al PIB; duplicar esa contribución en los países menos adelantados.

3. Aumentar el acceso de las pequeñas empresas, en particular en los países en desarrollo, a los servicios financieros, incluido el acceso a créditos asequibles, y su integración en las cadenas de valor y los mercados.

4. Mejorar la infraestructura y reajustar las industrias para que sean sostenibles, usando los recursos con mayor eficacia y promoviendo la adopción de tecnologías y procesos industriales limpios y ambientalmente racionales; que todos los países adopten medidas de acuerdo con sus capacidades respectivas.

5. Aumentar la investigación científica y mejorar la capacidad tecnológica de los sectores industriales de todos los países, en particular los países en desarrollo, entre otras cosas fomentando la innovación y aumentando el número de personas que trabajan en el campo de la investigación y el desarrollo por cada millón de personas, así como aumentando los gastos en investigación y desarrollo de los sectores público y privado.

6. Facilitar el desarrollo de infraestructuras sostenibles y resilientes en los países en desarrollo con un mayor apoyo financiero, tecnológico y técnico.

7. Apoyar el desarrollo de tecnologías nacionales, la investigación y la innovación en los países en desarrollo, en particular garantizando un entorno normativo propicio a la diversificación industrial y la adición de valor a los productos básicos.

8. Aumentar significativamente el acceso a la tecnología de la información y las comunicaciones; facilitar el acceso universal y asequible a Internet en los países menos adelantados.

Fuente: ONU (2015). 
dicciones dado el contexto productivo e institucional en el mundo. Moore (2015) señala que en el marco de la globalización, los procesos y estructuras económicas promueven el empleo barato que no comporta un trabajo digno. La experiencia ha mostrado que el proceso de cambio estructural asociado con la industrialización puede causar la pérdida de empleos en algunos sectores, por lo que tanto la política industrial como la política social deben estar alineadas de manera cercana para asegurar la protección de los trabajadores vulnerables.

De manera similar, el crecimiento económico históricamente ha mostrado contraposiciones con objetivos medio ambientales y de uso eficiente de los recursos. En ese sentido, Robert Solow (citado en Stoll, 2008) manifestó que el crecimiento económico continuo se veía amenazado porque era destructivo para el medio ambiente y dependía excesivamente de recursos naturales escasos. Uno de los desafíos centrales del crecimiento a través de la industrialización es la implantación de nuevas formas menos intensivas en el uso de energía y generación de carbono.

Según Moore (2015), a pesar de sus limitaciones los ods ofrecen una oportunidad para las sociedades y los gobiernos de atender y alcanzar metas específicas de desarrollo. Además permiten plantear escenarios socialmente más sensibles a través de cambios en el antiguo modelo de crecimiento. En el siguiente apartado se discute la situación de México a la luz de la Agenda 2030, así como las implicaciones para la definición de la política pública mexicana en materia de desarrollo económico.

\section{LA SITUACIÓN ACTUAL DE MÉXICO EN EL MARCO DE LA AGENDA ECONÓMICA INTERNACIONAL}

El documento "Indicators and Monitoring Framework for the Sustainable Development Goals. Launching a Data Revolution for the SDGs" (Sustainable Development Solutions Network, 2015) propone indicadores para dar seguimiento al alcance de los ods y señala que en cada país la evaluación dependerá de la existencia de información comparable internacionalmente, de los indicadores que se puedan construir con los datos disponibles localmente, y del avance en una agenda paralela de desarrollo de nuevas fuentes de información.

El gobierno mexicano junto con el Programa de las Naciones Unidas para el Desarrollo y la Agencia Mexicana de Cooperación Internacional para el Desarrollo lanzaron una plataforma piloto donde publica su propuesta de in- 
dicadores para el monitoreo de los objetivos y metas de la Agenda 2030. El cuadro 2 muestra la propuesta de indicadores del gobierno mexicano correspondientes a los objetivos 8 y 9 .

El desarrollo de instrumentos de monitoreo de los ods, tanto en México como a escala internacional, se muestra aún limitado en captar la naturaleza de varias de las metas establecidas para cada uno de los objetivos. En la propuesta para México, por ejemplo, se observa la ausencia de indicadores para monitorear aspectos como la erradicación de trabajo forzoso, la protección de derechos laborales y entornos de trabajo seguros, la capacidad de las instituciones financieras, la ampliación del acceso a servicios financieros o la capacidad tecnológica. Adicionalmente, se carece en la mayoría de los casos de parámetros de referencia para evaluar el cumplimiento de los países. ${ }^{3}$ Se requiere, en consecuencia, ampliar la gama de indicadores, evaluar su proximidad con lo establecido en cada una de las metas de desarrollo, y fijar parámetros referenciales. Esta es una tarea que se ha vislumbrado, pero que se ve limitada por la disponibilidad y comparabilidad de información entre países. Debido a la multiplicidad de metas e indicadores, a partir de una selección de aquellos que consideramos más generales e indicativos, se pretende brindar un panorama y diagnóstico síntesis que permita fijar el punto de partida para evaluar futuros avances en materia de crecimiento, empleo e industrialización en México conforme a la Agenda 2030.

Cuadro 2. Indicadores propuestos para el monitoreo en México de los objetivos 8 y 9

\section{Objetivo $8 \quad$ Objetivo 9}

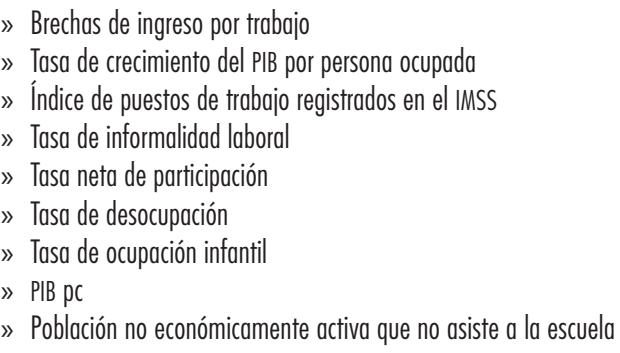

Fuente: htrp://pnud.carto.mx

\author{
» Número de suscriptores a teléfonos celulares \\ móviles por cada 100 habitantes \\ » Número de suscriptores a Internet de banda \\ ancha fija por cada 100 habitantes \\ »Porcentaje de viviendas que cuenta con Internet \\ de banda ancha \\ »Usuarios de Internet
} desarrolladas que sí estipula la meta 1 del objetivo 8. 


\section{Crecimiento económico y trabajo decente}

Las tasas de crecimiento del PIB por persona ocupada son una medición de la evolución de la productividad laboral en el país. El crecimiento de la productividad ha sido limitado (apenas por arriba de 3\% promedio anual) y volátil en el periodo 1996-2014 (véase gráfica 5). Este comportamiento hace vislumbrar retos y problemas sustanciales para alcanzar un crecimiento sostenido de al menos 7\% anual en los años de vigencia de la Agenda 2030, y permite advertir la necesaria revisión de metas realistas y alcanzables en estos rubros acorde a la actual situación de cada país.

El objetivo 8 también expresa preocupaciones torales acerca de la implementación de las legislaciones y los compromisos internacionales sobre trabajo decente (fomento del trabajo productivo, la protección de derechos laborales, obtención de ingresos adecuados, la protección y seguridad social, y el diálogo social). En este rubro se ubican otra serie de desafíos para el cumplimiento de la agenda internacional. Si bien el gobierno mexicano ha ratificado 78 de los 185 convenios de la OIT referidos a distintos rubros del ámbito laboral (empleo, salarios, condiciones de trabajo, seguridad social, trabajo femenil e infantil, libertad sindical, inspección en el trabajo, consulta tripartita y diálogo social), ha ratificado seis de los ocho convenios fundamentales de la organización y uno de los dos relativos a la libertad sindical y a la negociación colectiva, México es un país con un alto nivel de incumplimiento (Bensusán, 2009).

Gráfica 5. Tasa de crecimiento del PIB por persona ocupada (\%), 1996-2014

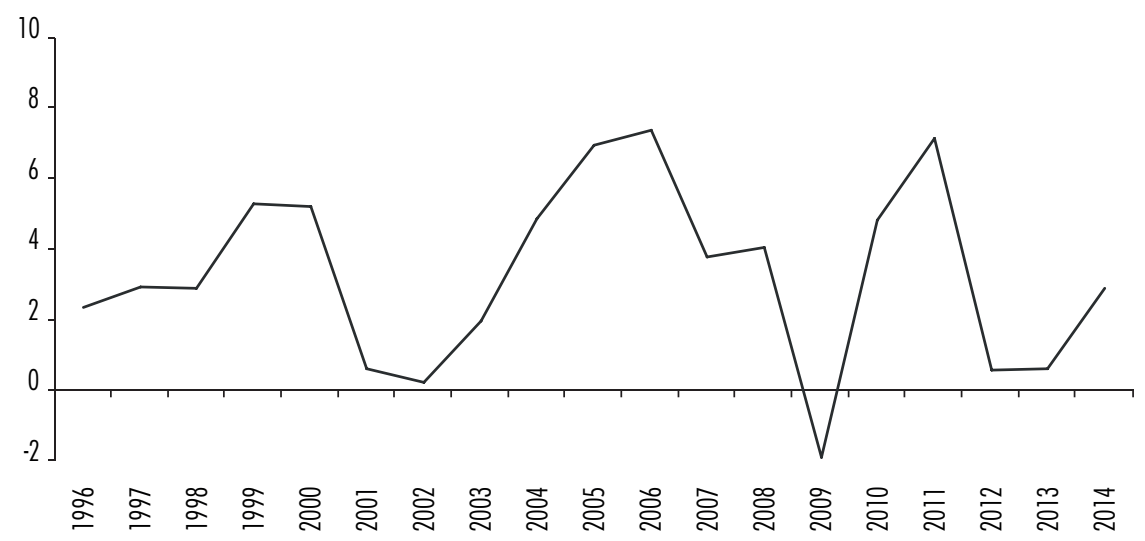

Fuente: Banco Mundial. 
Para evaluar algunas dimensiones clave del mercado laboral mexicano se revisan los datos disponibles sobre las tasas de desocupación, las brechas de ingreso y la tasa de ocupación infantil. Las tasas de desocupación han permanecido relativamente bajas (oscilan en el 5\%), indicando así que casi la totalidad de la población económicamente activa se encuentra empleada. Las tasas de desocupación más altas se observan en 2009, sin embargo, no alcanzan el 7\%. En el caso de las mujeres hay una tendencia a experimentar tasas más elevadas (véase gráfica 6).

Si bien las tasas de desempleo en el país son bajas, los problemas estructurales en el mercado de trabajo dificultan alcanzar metas de trabajo decente. De acuerdo con Hata (2010) alrededor de una cuarta parte de los nuevos puestos de trabajo no gozan de seguridad social, el sector informal tiende a crecer y a enmascarar problemas de desempleo, el empleo temporal y los ajustes internos en la cantidad de trabajo se vuelven prácticas crecientes. Además, se presentan altas tasas de rotación, una alta movilidad entre el sector formal y el informal, y una tercerización y precarización de los puestos de trabajo, siendo los más afectados los trabajadores jóvenes, aquellos con mayor nivel educativo y las mujeres (Rodríguez Vargas, 2007).

La tasa de informalidad, definida como la proporción de la población ocupada laboralmente vulnerable, ya sea por la naturaleza de la unidad económica en la que trabajan o por carecer de un vínculo laboral no reconocido por su fuente de trabajo de acuerdo con el orden legal vigente, está por arriba del $60 \%$ de la población ocupada total, aunque existen fuertes variaciones entre los estados del país (véase figura1).

La brecha nacional de ingresos por trabajo, que se mide como la diferencia entre los ingresos laborales promedio entre los hombres y las mujeres, muestra una reducción entre 2008 y 2012 (véase figura 2). El sostenimiento de esta tendencia contribuirá de manera positiva a alcanzar metas específicas de la agenda económica y en materia de reducción de las desigualdades.

Según las cifras oficiales, la tasa promedio nacional de ocupación infantil se ha reducido de 13 a 9\% entre 2007 y 2013 (véase figura 3). Se presentan diferencias considerables entre los estados de la República mexicana, siendo Guerrero la entidad con las tasas más altas. La tendencia decreciente de este indicador representaría otro signo alentador en materia del cumplimiento de los oDs. 


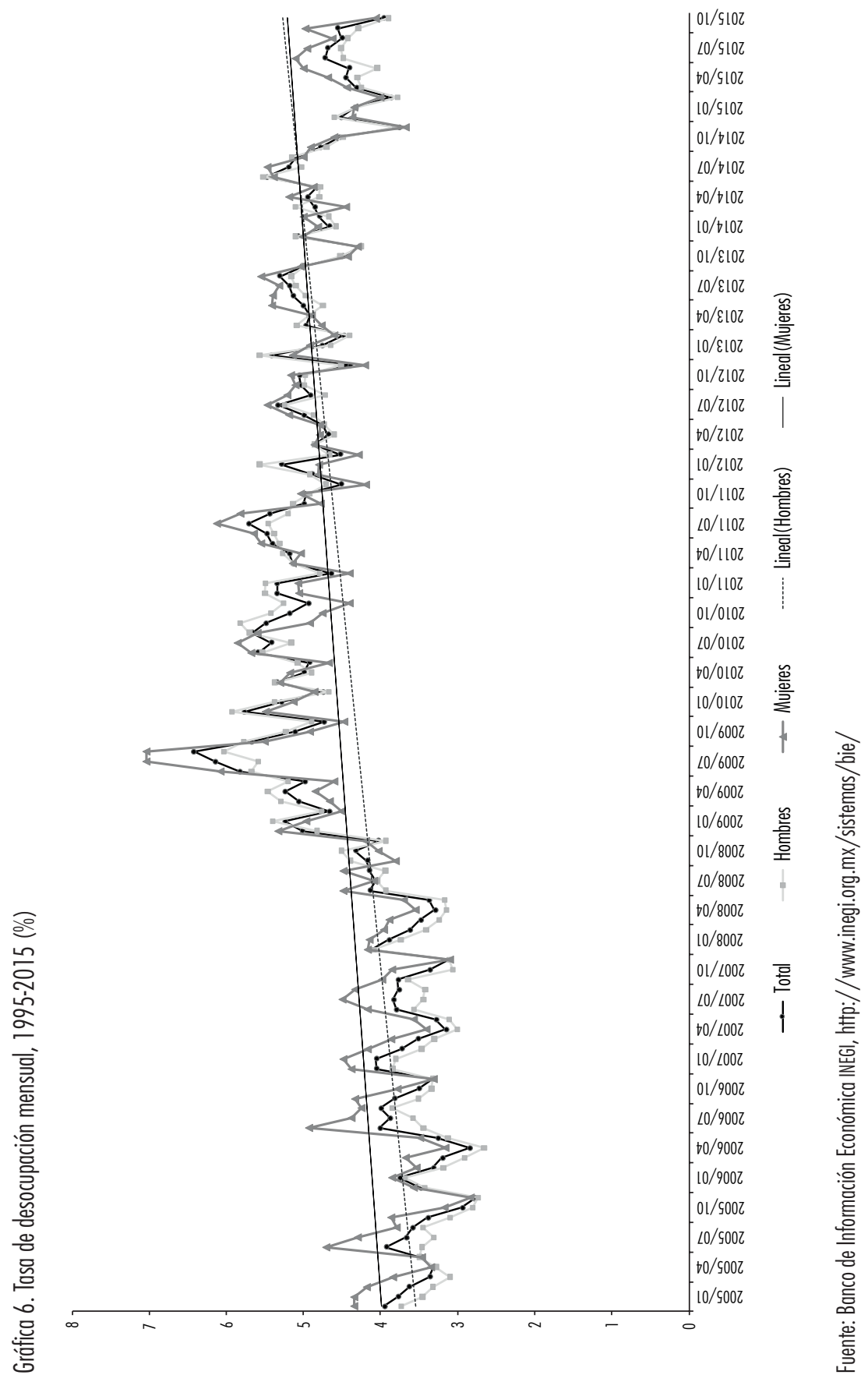


Figura 1. Tasa de informalidad estatales y promedio (\%)

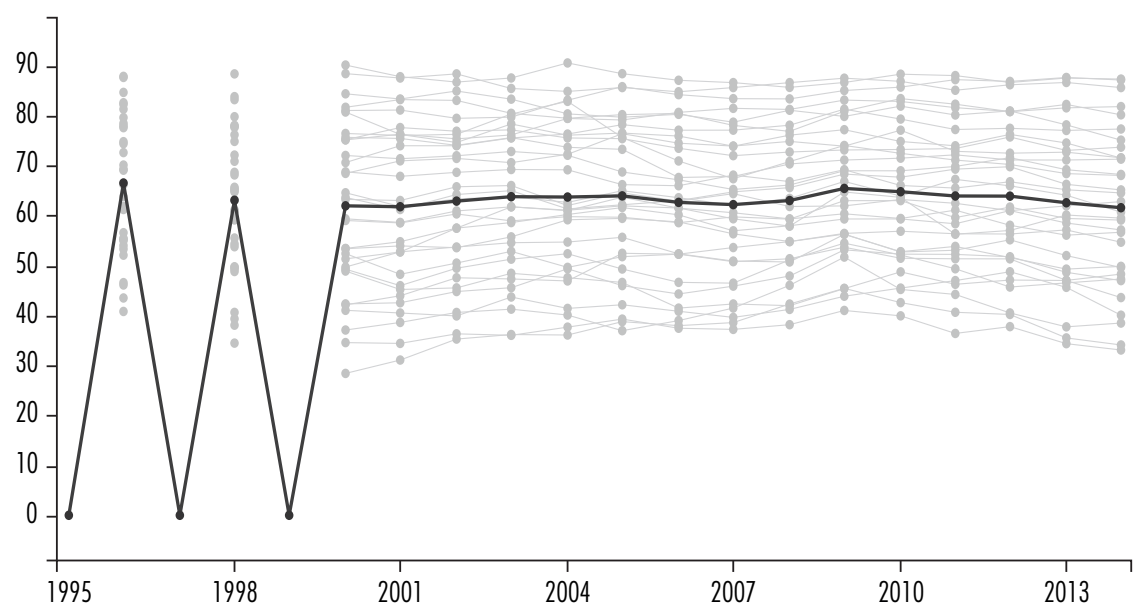

Fuente: http://agenda2030.datos.gob.mx

Figura 2. Brechas de ingreso por trabajo estatales y nacional, 2008-2012

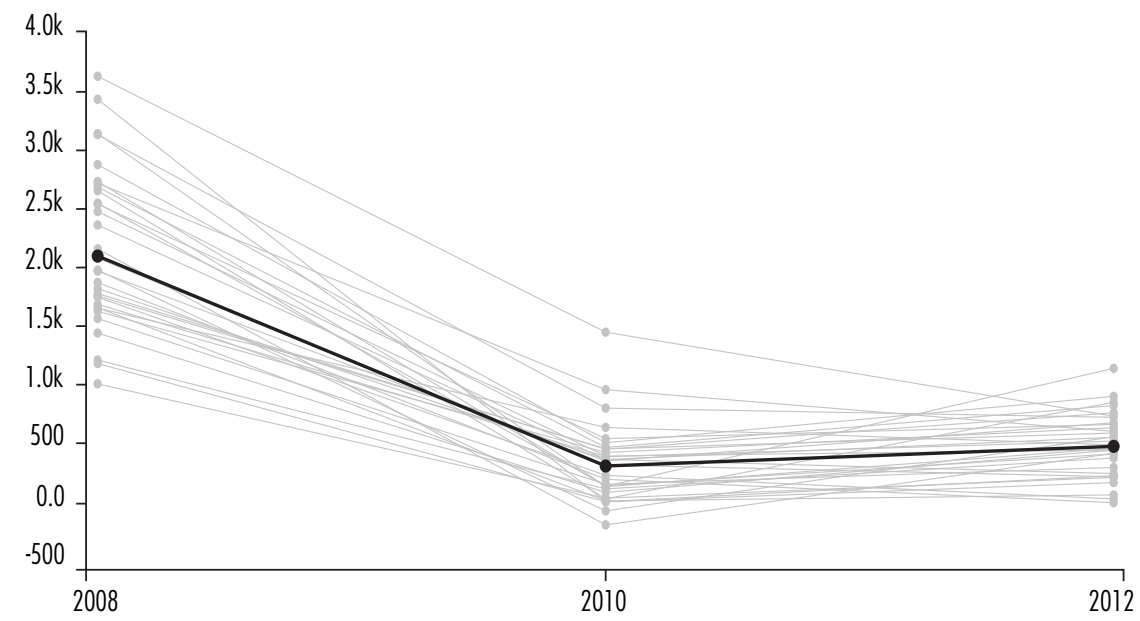

Fuente: hitp://agenda2030.datos.gob.mx 
Figura 3. Tasas de ocupación infantil estatales y nacional, 2007-2013

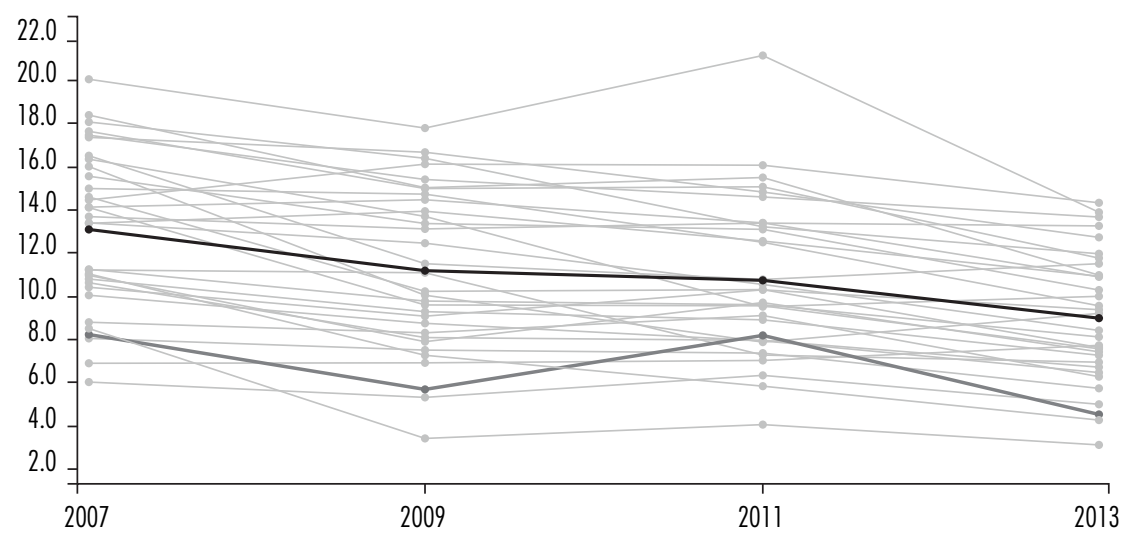

Fuente: http://agenda2030.datos.gob.mx

\section{Industria, innovación e infraestructura}

En referencia al cambio sectorial de la economía mexicana, las cifras del Banco Mundial señalan que entre 1988 y 2011 el empleo industrial como porcentaje del empleo total alcanzó en promedio alrededor de $25 \%$ y no presentó variaciones importantes a través del periodo (véase gráfica 7). Anteriormente se ha señalado que la economía mexicana se ha orientado mayormente a los servicios y el comercio, sectores que se han caracterizado por su baja productividad y tecnología.

En la definición de la Agenda 2030 la industrialización implica no sólo un cambio en la composición sectorial de la economía sino una transformación industrial guiada por el avance tecnológico y la innovación. Al respecto, México enfrenta un evidente rezago al destinar escasos recursos a actividades de investigación y desarrollo: en 1996 el gasto en el rubro representó 0.26 puntos porcentuales del PIB y en 2011 su gasto no alcanzaba el medio punto porcentual (véase gráfica 8). En comparación con países desarrollados como Japón (3.5\%) y Estados Unidos (2.8\%) o países emergentes como China (2\%) y la República de Corea (4.2\%), México destinó apenas 0.5\% de su PIB en 2015.

En cuestión de infraestructura el indicador que se propone en la plataforma mexicana es el porcentaje de viviendas con conexión de banda ancha. La figura 4 muestra el acelerado crecimiento en este indicador, presentando un porcentaje casi nulo en 2000 y rebasando $45 \%$ en 2014, aunque permanecen rezagos en la cobertura. 
Gráfica 7. Empleo industrial como proporción del total (\%), 1988-2012

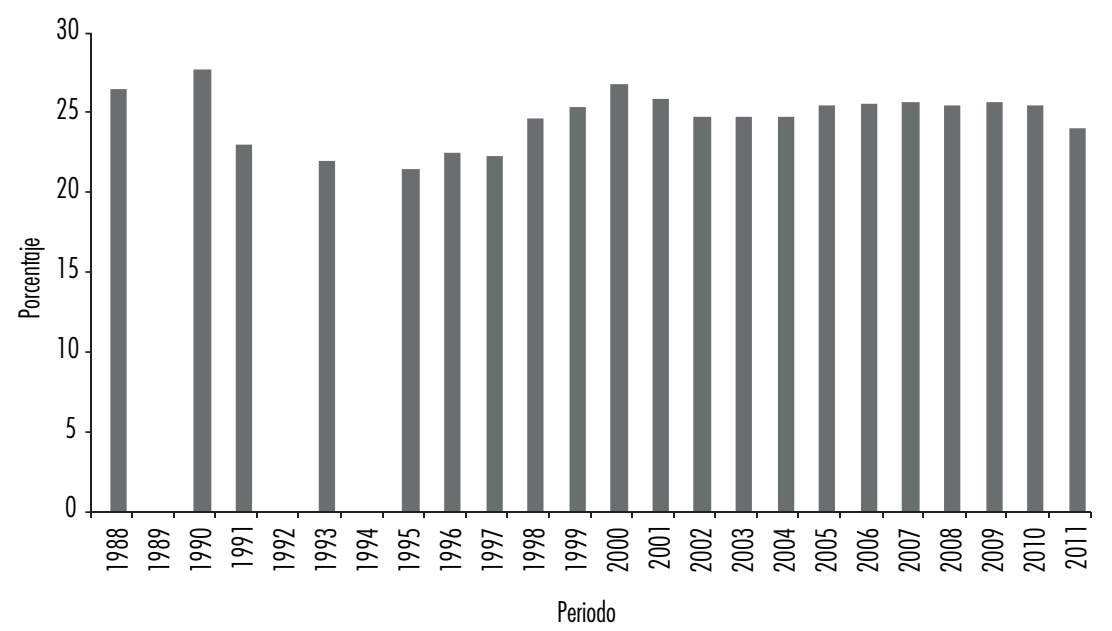

Fuente: Banco Mundial.

Grática 8. Gasto en I\&D como \% del PIB, 1996-2011

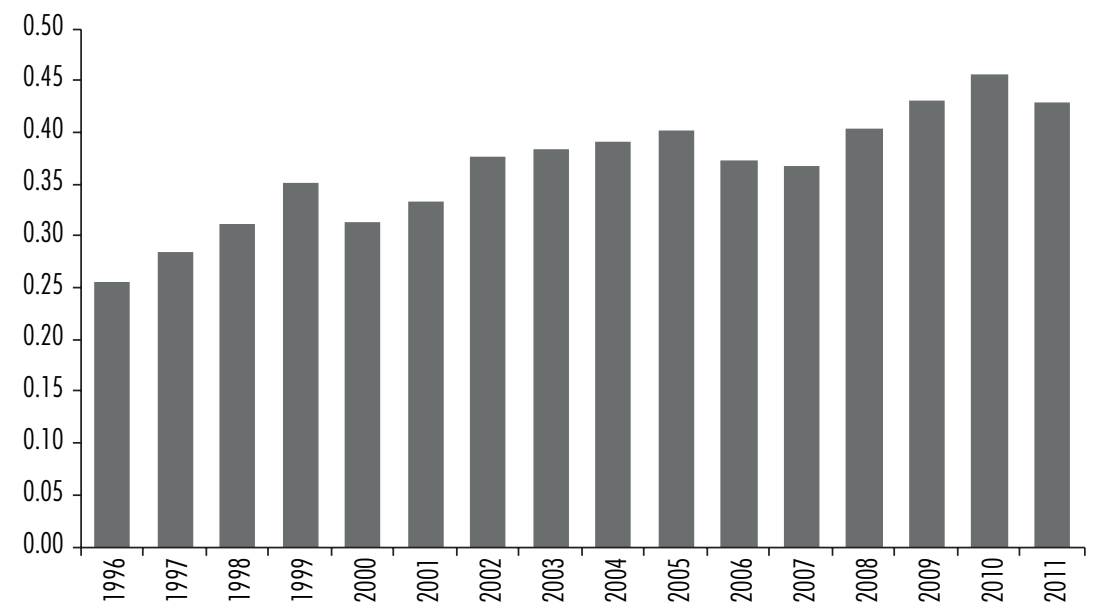

Fuente: Banco Mundial. 
Figura 4. Porcentaje de viviendas que cuentan con Internet de banda ancha, 2000-2014

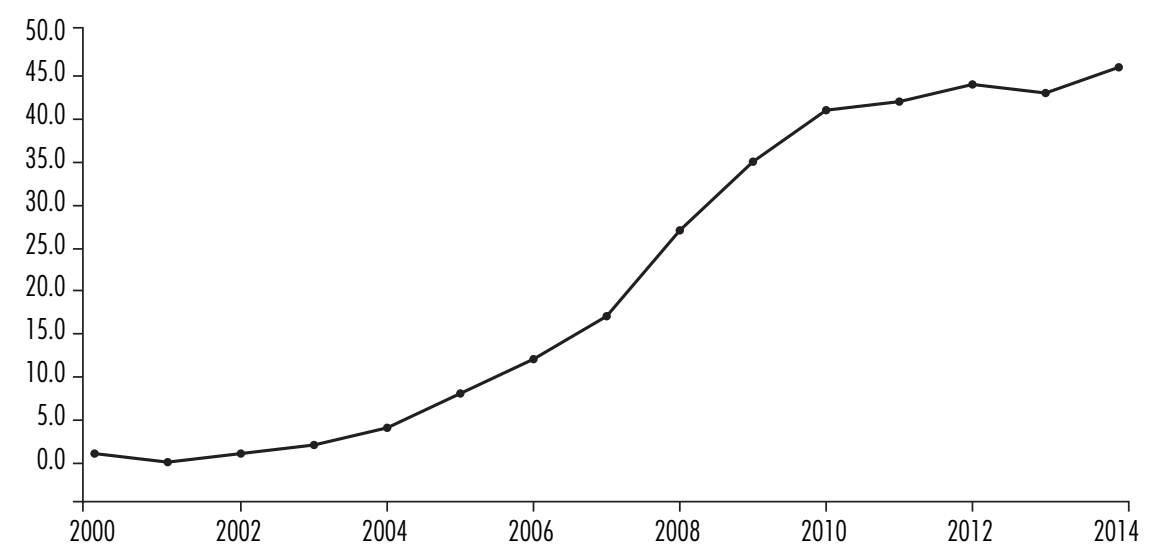

Fuente: http://agenda2030.datos.gob.mx

Los datos revisados permiten identificar los problemas en el desarrollo económico nacional que se asocian con el escaso crecimiento de la productividad, problemas estructurales en el mercado laboral -principalmente la informalidad que se asocia a situaciones de precarización, bajos salarios, inestabilidad y poca o nula seguridad y protección social-. Una segunda serie de problemas se refiere al carácter del cambio sectorial de la economía mexicana y los pocos recursos que incentiven el desarrollo tecnológico y la actividad innovadora. A la luz de lo poco desarrollado del sistema de indicadores quedan temas por evaluar como el de la infraestructura para el crecimiento. Asimismo, la cantidad de metas y dimensiones que involucra lo dispuesto en la Agenda 2030 plantea de entrada una complejidad para el diagnóstico más completo en cada una de las naciones, en este caso la mexicana.

\section{ALCANCES Y LÍMITES DE LAS POLÍTICAS PÚBLICAS DE DESARROLLO ECONÓMICO EN EL MARCO DE LOS ODS}

El problema del bajo crecimiento económico mexicano ha sido objeto de múltiples interpretaciones y debates en los ámbitos académico y político. Algunas explicaciones esgrimidas se refieren a factores primordialmente externos (Guillén, 2000; Calva, 2001; Palazuelos, 2001; Esquivel, 2010): las políticas derivadas del Consenso de Washington que se implementaron sin considerar 
las particularidades de la economía nacional; la dependencia de la economía mexicana respecto al ciclo económico estadounidense; el pobre crecimiento del sector externo; el déficit sistemático en la balanza en cuenta corriente y la alta dependencia de las importaciones de bienes intermedios y de capital; la apertura; y el tipo de cambio real apreciado.

Según otro conjunto de autores (Perrotini, 2004; Ros, 2008; De María y Campos et al., 2009) el bajo crecimiento se explica por factores predominantemente internos: el deficiente financiamiento interno; políticas monetarias y fiscales de carácter restrictivo; la reducida tasa de acumulación de capital y la baja tasa de inversión privada; la disminuida inversión pública; el desmantelamiento de la política industrial y la falta de financiación bancaria; la atonía de la inversión, y la ausencia de estrategias y políticas apropiadas en las esferas sectorial y regional.

A este respecto, ¿`cuál es la postura tomada por el gobierno al que corresponde la posible adopción de la Agenda 2030 de desarrollo internacional? En el diagnóstico ortodoxo la falta de reformas estructurales y la prolongada escasez de crédito crearon cuellos de botella que han bloqueado un crecimiento mayor y llevaron a la disminución del dinamismo exportador (Martínez et al., 2004). En esta línea se inscribe la propuesta reformista iniciada en 2012 en la que existen cinco elementos de diagnóstico sobre las barreras al crecimiento económico mexicano: 1) los incentivos a la informalidad son causa del estancamiento de la productividad; 2) la rigidez del mercado de trabajo es un freno a la creación del empleo; 3) la falta de competencia es un obstáculo a la innovación y a la competitividad; 4) hay escasez de capital humano, y 5) abundan las fallas institucionales.

En concordancia con estos factores se han formulado varias de las reformas estructurales de la historia mexicana reciente. Entre ellas, las más trascendente en materia de desarrollo económico, se encuentran la reforma laboral, la educativa, la de telecomunicaciones y competencia económica, la hacendaria, la financiera, y la energética. Estas reforzaron el espíritu aperturista y privatizador de la política económica conforme al precepto de alcanzar la eficiencia en los mercados. La compatibilidad de esta orientación reformista (véase cuadro 3) con las políticas nacionales necesarias para alcanzar las metas de la agenda internacional de desarrollo es una cuestión a evaluar.

Entre las contradicciones más significativas de las reformas estructurales mexicanas con respecto a la Agenda 2030 se identifica la flexibilización laboral y la subcontratación que son propiciadas por la reforma laboral y que se contraponen con el principio de trabajo decente. De manera similar, es posible señalar los limitados alcances de la reforma educativa para mejorar el capital 


\section{Alejandra Trejo Nieto}

Cuadro 3. Reformas estructurales, 2012-2018

\begin{tabular}{|c|c|}
\hline Reforma & Objetivos \\
\hline Laboral & $\begin{array}{l}\text { i) Disminuir el costo de contratación e impulsar el empleo formal a través de nuevas } \\
\text { modalidades de contratación que incluyen contratos flexibles de trabajo. ii) Proveer certeza } \\
\text { jurídica y reducción de los costos de separación del trabajo, a través de acuerdos en caso de } \\
\text { demandas laborales y topes a las compensaciones por despidos no justificados. iii) Reestructurar } \\
\text { la organización del trabajo dentro de las empresas (la productividad y las habilidades laborales } \\
\text { toman prioridad sobre la antigüedad como el principal criterio para ocupar plazas vacantes). }\end{array}$ \\
\hline
\end{tabular}

Educativa Elevar la calidad de la educación en México a estándares internacionales. Implementar un sistema profesional para evaluar, contratar, asignar y otorgar promociones a los maestros, y al mismo tiempo reducir la interferencia de los sindicatos en el acceso a las plazas docentes $\mathrm{e}$ integrar una proporción mayor de la fuerza laboral al sector formal.

Telecomunicaciones Promover la competencia en el sector y proveer acceso más barato y amplio a los servicios y competencia de telecomunicaciones: i) permitir una mayor participación de empresas extranjeras en ciertos económica segmentos del sector, incluyendo comunicaciones satelitales; ii) Crear un nuevo órgano regulatorio que otorgue y revoque concesiones, decrete escisiones y venta de activos para eliminar prácticas anti-competitivas, y iii) Disminuir el uso de prácticas legales para retrasar la aplicación de resoluciones administrativas.

Hacendaria Ampliar la base de los impuestos al ingreso y al consumo, simplificar su pago, eliminar tratamientos especiales y fortalecer los ingresos tributarios. Constituir un nuevo régimen fiscal de incorporación y un cambio en la estructura de las cuotas patronales. Incrementar la recaudación de los gobiernos locales y la transparencia en las transferencias a Entidades Federativas y Municipios. Mantener un nivel de deuda pública sostenible.

Financiera Promover la competencia en el sector para ampliar la penetración de los servicios y cumplir dos objetivos fundamentales: aumento y abaratamiento del crédito. La reforma también redefine el mandato de la Banca de Desarrollo e introduce mejoras al marco legal para el otorgamiento y ejecución de garantías, asi como modificaciones a los procesos de resolución de controversias mercantiles.

Energética Incrementar la inversión en el sector energético. Posibilitar contratos en el sector de hidrocarburos y flexibilizar los mecanismos de asociación del Estado en el sector eléctrico, así como mantener la prohibición existente a las concesiones en ambos sectores. Eliminar el monopolio existente en las actividades de exploración, producción y refinación de hidrocarburos mediante adecuaciones al artículo 28 constitucional.

Fuente: elaboración propia. 
humano; los limitados alcances que la reforma financiera pueda tener para mejorar el acceso a los créditos a la producción; la carencia de propuestas para el uso eficiente y responsable de energéticos; la ausencia del tema ambiental y el de la sustentabilidad; la efectiva promoción de competencia en el sector de las telecomunicaciones y los efectos de la reforma en las tarifas para distintos usuarios; el alcance de la reforma hacendaria para ampliar la base fiscal y alcanzar presupuestos sostenibles. En varios casos, el impacto de las reformas en el cumplimiento de la Agenda 2030 estará supeditado a su implementación práctica, más que a su mera formulación enunciativa. En el peor escenario las reformas estructurales se sumarán a aquellas que se han traducido en un crecimiento bajo, con creciente desigualdad y efectos inciertos sobre la erradicación de la pobreza.

\section{COMENTARIOS FINALES}

En la historia mexicana reciente, la política económica ha priorizado la estabilización y ha tenido como objetivo eliminar las regulaciones, los monopolios de Estado, y los aranceles, así como ubicar a México en el marco de una economía de "libre mercado" y de competencia global. En materia de fomento productivo se han articulado una serie de programas para fortalecer la Inversión Extranjera Directa o la actividad maquiladora de exportación a través de incentivos financieros o fiscales. Además, los esquemas de fomento se subsumieron en programas pro competitividad de sectores o regiones, es decir, han sido selectivos. A pesar de los intentos por detonar una importante dinámica económica el crecimiento ha sido escaso, no se han reducido brechas económicas, no se ha fortalecido el mercado laboral, ni se ha mejorado el nivel de vida de la población de manera inclusiva y sustentable.

Los retos de la política económica mexicana son numerosos y complejos; sólo por mencionar algunos: el fortalecimiento de cadenas productivas, el desarrollo de proveedores nacionales, el aumento del contenido nacional de las exportaciones, y propiciar efectos multiplicadores en el resto de la economía. A ello se une la necesidad de fortalecer el mercado interno. Además en el contexto de los ods se requiere evaluar y minimizar el impacto ambiental de la actividad productiva, mejorar la eficiencia energética, favorecer el uso de nuevas fuentes de energía, e implementar una visión inclusiva, de derechos laborales y trabajo decente. Aunque en nuestra discusión no se aborda el tema de la desigualdad, el panorama económico está lleno de profundas y significativas disparidades de distinta naturaleza. El desarrollo equilibrado y 
sustentable demanda incorporar la dimensión territorial, así como transferir funciones a niveles de gobierno subnacionales.

En el ámbito de las reformas estructurales recientes es indispensable evaluar su compatibilidad con el fomento de investigación y desarrollo, la innovación tecnológica, el financiamiento desde la banca comercial y el otorgamiento de créditos de la banca de desarrollo. Asimismo, un tema central se refiere a la inversión pública y las alianzas público-privadas para la construcción de infraestructura.

La implementación de una política industrial estratégica que se dé en el marco de una política económica y social amplia puede convertirse en el punto de arranque de una agenda de política pública tendiente a alcanzar los objetivos económicos del desarrollo sustentable e inclusivo. Es posible aprender de las reflexiones y experiencias de otros países y en este sentido se abren posibilidades de cooperación internacional. Países que en los años sesenta presentaban un grado de desarrollo similar al mexicano, actualmente se encuentran pasos adelante en materia económica y social. Los "tigres" asiáticos y la economía China deben buena parte de su éxito a una fuerte y bien pensada política industrial, que propicia un "industrial upgrading" (Méndez, 1997; Brown y Hernández, 2015). En países europeos, Estados Unidos, Canadá, Japón, China o Brasil las políticas industriales activas han servido para enfrentar crisis, rescatar sectores, o promover el desarrollo regional equilibrado. En varios de estos casos, destacan el papel del aprendizaje y la innovación dentro de un enfoque hacia el crecimiento, el desarrollo y el progreso (Stiglitz y Greenwald, 2015). El tema de la sostenibilidad y sustentabilidad resulta más complejo por las contradicciones ya mencionadas.

La política industrial tendría que elaborarse en torno a dos grandes ejes programáticos: un plan de desarrollo y transformación industrial y la promoción de un verdadero cambio tecnológico estructural. Elaborar tal estrategia requiere un diagnóstico minucioso del estado actual de la industria nacional considerando: tamaños, sectores, propiedad de origen, contexto local, etcétera. El éxito de las políticas de desarrollo económico demanda una adecuada gobernanza y reformas institucionales, la compatibilidad entre instrumentos de política y las capacidades del sector público, necesita ingresos y recursos para subsidiar o apoyar la investigación y el aprendizaje, y un buen desempeño de la banca de desarrollo; por ejemplo, para financiar y fortalecer la infraestructura para el desarrollo socioeconómico del país.

Sin embargo, varios factores de ineficacia en el vigente marco institucional han sido la fragmentación del poder político que se explica por la aparición de nuevos y heterogéneos actores con fuerte poder, los problemas de déficit de 
ciudadanía, gobernabilidad, Estado de derecho, la corrupción e inseguridad. Debido a ello la base institucional para la implementación de los instrumentos de desarrollo, así como la estructura y naturaleza de los incentivos que enfrentan los agentes económicos será un componente definitorio en el avance de la agenda económica. Esta serie de elementos también definirán el rumbo de los principales problemas en otros ámbitos del desarrollo. La Agenda 2030 es un recordatorio de los problemas, retos y temas pendientes en esta materia en el país.

\section{BIBLIOGRAFÍA}

Acevedo Fernández, Ernesto (2006), "Inflación y crecimiento económico en México: una relación no lineal”, Economía Mexicana, Nueva Época, vol. xv, núm. 2, México, Centro de Investigación y Docencia Económicas, segundo semestre, pp. 199-249.

Bensusán, Graciela (2009), "Estándares laborales y calidad de los empleos en América Latina”, Perfiles Latinoamericanos, núm. 34, México, Flacso, julio-diciembre, pp. 13-49.

Calderón, Cuauhtémoc e Isaac Sánchez (2012), “Crecimiento económico y política industrial en México”, Problemas del Desarrollo, vol. 43, núm. 170, México, unAM-IIEc, julio-septiembre, pp. 125-154.

Calva, José (2001), "La economía mexicana en recesión”, Problemas del Desarrollo, vol. 32, núm. 126, México, UNAM-IIEc, julio-septiembre, pp. 237 252.

Cárdenas, Enrique (2015), El largo curso de la economía mexicana, México, FCE.

Cota Yáñez, Rosario y Alberto Navarro Alvarado (2015), "Análisis del mercado laboral y el empleo informal mexicano", Papeles de Población, vol. 21, núm. 85, México, uaemex, julio-septiembre, pp. 211-249.

De María y Campos, Mauricio, Lilia Domínguez, Flor Brown y Armando Sánchez (2009), El desarrollo de la industria mexicana en su encrucijada, Universidad Iberoamericana de la Ciudad de México e Instituto de Investigaciones sobre Desarrollo Sustentable y Equidad Social, México.

Escribano, Gonzalo (2010), Teorías del desarrollo económico, Universidad Nacional de Educación a Distancia (UNED), Madrid, España. http://sistemaucem.edu.mx/bibliotecavirtual/oferta/licenciaturas/derecho/LDE318/ teorias_del_desarrollo_economico.pdf 
Esparza, Martín (2014), "México y sus 30 años sin crecimiento económico", http://www.contralinea.com.mx/archivo-revista/index.php/2014/06/08/ mexico-sus-30-anos-sin-crecimiento-economico/

Esquivel, Gerardo (2010), "De la inestabilidad macroeconómica al estancamiento estabilizador: el papel del diseño y la conducción de la política económica", en Nora Lustig (coord.), Crecimiento económico y equidad, México, El Colegio de México.

Fernández Espejel, Gabriel (2013), "Los factores del crecimiento económico en México. Centro de Estudios Sociales y de Opinión Pública”, Documento de Trabajo núm. 153.

Guillén, Arturo (2000), México hacia el siglo XXI. Crisis y modelo económico alternativo, México, Plaza y Valdés-UAM.

Haber, Stephen (1993), "La industrialización de México: historiografía y análisis", Historia mexicana, vol. xLII, núm. 3, México, El Colegio de México, enero-marzo, pp. 649-688.

Hata, Keiko (2010), "Labor and Social Security Reforms in México: from the Perspective of State-Labor Relationships", en K. Usami (ed.), Nonstandard Enployment under Globalization. Flexible Work and Social Security in the Newly Industrializing Countries, London, Palgrave McMillan.

ICSU, ISsC (2015), Review of Targets for the Sustainable Development Goals: The Science Perspective, International Council for Science, International Social Science Council, Paris, Francia.

Loría, Eduardo (2009), "Sobre el lento crecimiento económico de México. Una explicación estructural”, Investigación Económica, vol. 68, núm. 270, pp. 37-68.

Martínez, Lorenza, Aarón Tornell y Frank Westermann (2004), “Globalización, crecimiento y crisis financieras. Lecciones de México y del mundo en desarrollo", Trimestre Económico, vol. 71, núm. 282, México, FCE, pp. 251-351.

Méndez, José Luis (1997), "Veinte años de planeación industrial en México", Comercio Exterior, vol. 47, núm. 1, México, Bancomext, enero, pp. 50-56.

Moore, Henrietta L. (2015), "Global Prosperity and Sustainable Development Goals", Journal of International Development, vol. 27, núm. 6, John Wiley \& Sons, agosto, pp. 801-815.

Moreno-Brid, Juan Carlos e Igor Paunovic (2009), "Crisis financiera internacional y sus efectos en la economía mexicana”, Economía: Teoría y Práctica, Nueva Época, Número Especial, vol. 1, México, UAM-I, noviembre, pp. 63-80. 
Norris, Clement, Gustavo del Castillo Vera, James Gerber, William A. Kerr, Alan J. MacFadyen, Stanford Shedd, Eduardo Zepeda y Diana Alarcon (1999), North American Economic Integration. Theory and Practice, Reino Unido, Edward Elgar Publishing.

Organización de las Naciones Unidas (ONU) (2015), Proyecto de resolución remitido a la Cumbre de las Naciones Unidas para la aprobación de la Agenda para el Desarrollo de 2015 por la Asamblea General en su sexagésimo noveno periodo de sesiones, Nueva York.

Palazuelos Manso, Enrique (2001), "Desequilibrio externo y crecimiento económico en México: una perspectiva de largo plazo", ICE: Revista de economía, núm. 795, España, Información Comercial Española, noviembrediciembre, pp. 9-36.

Perrotini, Ignacio (2004), "Restricciones estructurales del crecimiento en México, 1980-2003”, Economía, vol. 1, núm. 1, México, unAM, pp. 86100.

Rodríguez Vargas, Miriam (2007), El empleo y las políticas activas del mercado de trabajo en México en un mundo globalizado (2002-2007), Tesis de Doctorado, Facultad Latinoamericana de Ciencias Sociales, México.

Ros, Jaime (2008). "La desaceleración del crecimiento económico en México desde 1982", El Trimestre Económico, vol. 75, núm. 299, México, FCE, julio-septiembre, pp. 537-560.

Stiglitz, Joseph y Bruce C. Greenwald (2015), La creación de una sociedad del aprendizaje. Un nuevo enfoque hacia el crecimiento, el desarrollo y el progreso social: conceptos básicos análisis, México, Crítica.

Stoll, Steven (2008), "Fear of fallowing. The Specter of a No-growth World", Harper's Magazine, March.

Sustainable Development Solutions Network (2015), "Indicators and a Monitoring Framework for the Sustainable Development Goals. Launching a Data Revolution for the sDGs", Leadership Council of the Sustainable Development Solutions Network, June.

Trejo Nieto, Alejandra y Odra A. Saucedo (2013), "Trabajo decente, política pública y responsabilidad social corporativa”, en David Castro y Reyna Rodríguez (coords.), El mercado laboral frente a las transformaciones económicas de México, México, Plaza y Valdés y Universidad Autónoma de Coahuila, pp. 205-233.

Verick, Sher e Iyanatul Islam (2010), "The Great Recession of 2008-2009: Causes, Consequences and Policy Responses", IZA Discussion Paper Series, núm. 4934, Germany, Institute for the Study of Labor, May, pp. 1-61. 
